NuRD complex came with the identification of other members, among their number a chromatin-remodelling protein. The final test was to see whether PID is involved in deacetylation in vivo. As expected, expression of PID inhibited p53 acetylation in an HDAC1-dependent manner. It also affected the cellular functions of p53; for example, treatment with PID blocked p53-mediated growth inhibition, expression of endogenous p21 and apoptosis. It seems, then, that $\mathrm{Gu}$ and colleagues have identified a protein that tips the balance towards the deacetylation - and, hence, inactivation - of p53, with obvious implications for its role in human cancer.

Alison Mitchell

(2) References and links ORIGINAL RESEARCH PAPER Luo, J. et al. Deacetylation of $p 53$ modulates its effect on cell growth and apoptosis. Nature 408, 377-381 (2000)

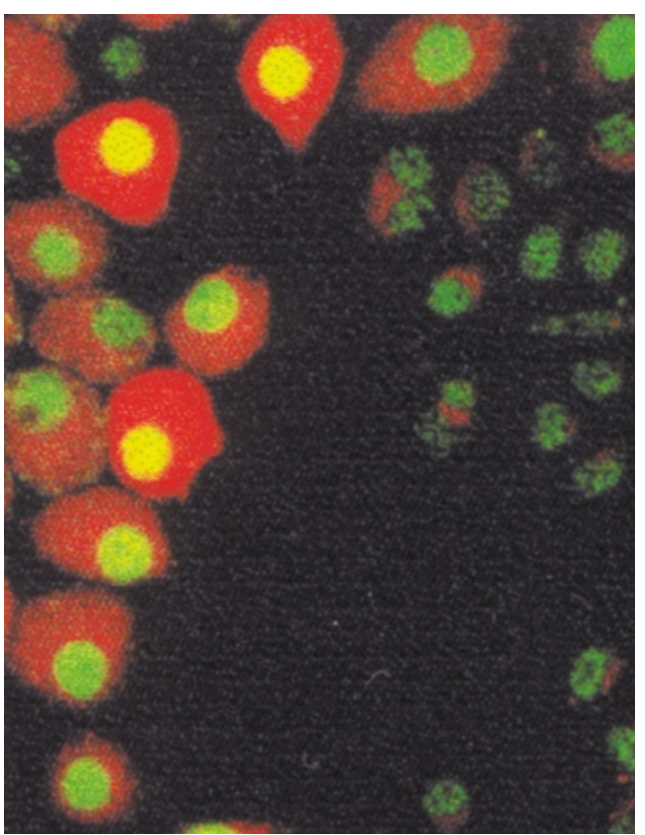

probably initiates the same molecular pathway. But in starting to identify some of the molecular elements that may be involved in this pathway, the authors may well have struck gold.

(0) References and links ORIGINAL RESEARCH PAPER Shen, C.-N., Slack, J. M. W. \& Tosh, D. Molecular basis of transdifferentiation of pancreas to liver. Nature Cell Biol. 2, 879-887 (2000)

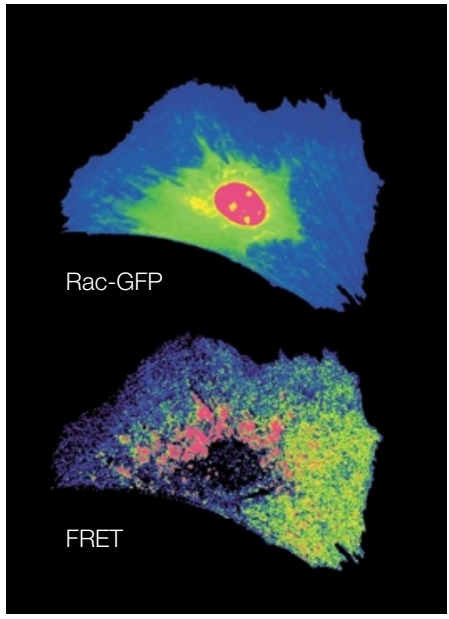

TECHNIQUE

\section{A certain FLAIR}

Small GTPases of the Rho family regulate vital cellular processes by controlling actin polymerization. As is the case for other signalling molecules, the effects of these GTPases are very focused in space and time. Wouldn't it be useful, then, to quantify their spatio-temporal dynamics of activation? Klaus Hahn and colleagues now report in Science how to do this.

The authors expressed Rac tagged with green-fluorescent protein (GFP), and microinjected at the same time PDB - a domain of PAK1 that specifically binds to active Rac-GTP - labelled with the dye Alexa. The sites of attachment of the fluorophores were chosen so that, when Rac and PDB interacted, GFP and Alexa would be close enough for fluorescence resonance energy transfer (FRET) to occur. With this experimental set-up, the authors could quantify in real time, in the same moving cell, the changing localization of Rac (GFP-Rac) and of Rac activation (FRET), and found them remarkably uncorrelated.

The method was called FLAIR, for 'fluorescence activation indicator for Rho proteins'. And, as the name says, there is no reason why it should not work for other GTPases of the Rho family, if an appropriate binding partner is chosen instead of PDB. Knowing the when and where of actin polymerization should open many doors for the study of actin-dependent processes, such as cell motility, shape generation or phagocytosis.

Raluca Gagescu

\section{9) References and links} ORIGINAL RESEARCH PAPER Kraynov, V. S. et al. Localized Rac activation dynamics visualized in living cells. Science 290, 333-337 (2000)
H I G H L I G H T S

\section{IN BRIEF}

\section{T-CELL SIGNALLING}

ERK5 is a novel type of mitogen-activated protein kinase containing a transcriptional activation domain.

Kasler, H. G., Victoria, J., Duramad, O. \& Winoto, A. Mol. Cell. Biol. 20, 8382-8389 (2000)

Mitogen-activated protein kinases (MAPKs) can translocate to the nucleus and activate transcription, but their effects have been assumed to be indirect. Kasler and colleagues now characterize a new type of MAPK — ERK5 — that has a potent transcriptional activation domain at its carboxyl terminus, as well as another domain that binds the transcription factor MEF2D. In T cells, maximal activation of MEF2D in response to calcium requires both domains and is blocked by the corepressor Cabin 1.

\section{CELL DIVISION}

Protein kinase $\mathrm{C}$ signalling mediates a program of cell cycle withdrawal in the intestinal epithelium.

Frey, M. R. et al. J. Cell Biol. 151, 763-777 (2000)

Why do most cells stop dividing when they differentiate? In developing intestinal epithelial cells, protein kinase $\mathrm{C}$ is activated as the cells climb the intestinal crypts. Frey at al. now couple activation of protein kinase $\mathrm{C}$ to a coordinated programme of downstream events: downregulation of mitotic cyclins and altered expression and phosphorylation of retinoblastoma protein and its relatives sends these cells down the pathway to quiescence.

\section{CELLULAR MICROBIOLOGY}

A PEST-like sequence in listeriolysin O essential for Listeria monocytogenes pathogenicity.

Decatur, A. L. \& Portnoy, D. A. Science 290, 992-995 (2000)

After Listeria monocytogenes is engulfed by its host cell, it lyses its phagocytic vacuole with the help of a secreted pore-forming toxin called listeriolysin $O$. This allows the bacterium to escape into the cytosol, where it can rapidly multiply. But what stops the toxin from destroying its home by lysing the plasma membrane too? The answer is simple: listeriolysin O contains a PEST-like sequence that targets it for degradation by the proteasome as soon as it comes in contact with the cytosol.

\section{PROTEIN METHYLATION}

\section{Carboxyl methylation of the phosphoprotein} phosphatase 2A catalytic subunit promotes its functional association with regulatiory subunits in vivo.

Wu, J. et al. EMBO J. 19, 5672-5681 (2000)

Several proteins can be modified by methylation of their carboxyl termini, but does this alter their function? Wu and colleagues show that it does - at least for protein phosphatase 2A (PP2A). They identify the yeast enzymes responsible for adding and removing the methyl group and, by manipulating these enzymes genetically, show that methylation alters the affinity of PP2A for different regulatory subunits. 